\title{
ROHHAD Sendromlu Olgunun King’in Amaca Ulaşma Kuramına Dayalı Bakımının
} Planlanması

\author{
Planning the Care of ROHHAD Syndrome Case Based on King's Theory of Goal
}

\author{
Attainment
}

\section{Yağmur ARTAN* iD, Yasemin YILDIRIM**iD, Fisun ŞENUZUN AYKAR**iD, Çiçek \\ FADILOĞLU*: iD}

\begin{abstract}
ÖZET
Giriş: ROHHAD (Rapid onset Obesity, Hypothalamic dysfunction, Hypoventilation and Autonomic Dysregulation); hipotalamik disfonksiyon, hipoventilasyon, otonomik disregülasyon ve hızlı başlangıçl obezite ile karakterize nadir görülen bir sendromdur. Literatürde bugüne kadar yüzün altında vaka bildirilmiştir. Etyolojik faktörler net olmamakla birlikte, otoimmün ve genetik faktörlerin hastalı̆̆ın genel tablosunda etkili olduğu düşünülmektedir.
\end{abstract}

Olgu Sunumu: ROHHAD Sendromu tanılı 17 yaşında kı hasta, kardiyak ve solunum arresti nedeni ile yoğun bakımda takip edilmiştir.

Tartışma: Karmaşı tanı ve tedavi süreci, ilerleyen prognoz nedeniyle hasta ve ailesi fiziksel, sosyal, psikolojik ve ekonomik boyutlarda sorun yaşamaktadır. Hemşireler, hasta ve ailesine kanıta dayalı uygulamalar sağlayarak destek olmalıdır.

Sonuç: Bu makalede yoğun bakımda takip edilen hastaya King'in Amaca Ulaşma Kuramı çerçevesinde uygulanan hemşirelik girişimleri incelenmiştir.

Anahtar Kelimeler: Bakım planı, hemşirelik teorisi, ROHHAD sendromu

\begin{abstract}
Introduction: ROHHAD (Rapid onset Obesity, Hypothalamic dysfunction, Hypoventilation and Autonomic Dysregulation); is a rare syndrome characterized hypothalamic dysfunction, hypoventilation, autonomic dysregulation and rapid onset obesity. Less than a hundred cases have been reported in the literature to date. Although etiological factors are not clear,believed that autoimmune and genetic factors are effective in the overall picture of the disease.

Case report: A 17-year-old girl diagnosed with ROHHAD Syndrome was monitored in the intensive care unit due to cardiac and respiratory arrest.

Discussion: Due to complicated diagnosis and treatment process and progressive prognosis, patient and her family have problems in physical, social, psychological and economic dimensions. Nurses should support the patient and family by providing evidence-based practices.

Conclusion: In this article, the nursing interventions applied to the patient who was monitored in the intensive care unit within the framework of King's Goal Attainment Theory were examined.
\end{abstract}

Keywords: Care planning, nursing theory, ROHHAD syndrome

Geliş Tarihi / Received: 19.06 .2020

Kabul Tarihi / Accepted: 09.08.2020

*Araş. Gör., Ege Üniversitesi Hemşirelik Fakültesi İç Hastalıkları Hemşireliği, İzmir
${ }^{* *}$ Prof. Dr., Ege Üniversitesi Hemşirelik Fakültesi İç Hastalıkları Hemşireliği, İzmir

Sorumlu Yazar / Corresponding Author: Yağmur ARTAN,ygmr-artan@hotmail.com 


\section{GİRIŞ̧}

ROHHAD (Rapid onset Obesity, Hypothalamic dysfunction, Hypoventilation and Autonomic Dysregulation; Hızlı başlangıçlı obezite, Hipotalamik disfonksiyon, Hipoventilasyon ve Otonomik Disregülasyon), bugüne kadar 78 hastada saptanan hızlı başlangıçlı obezite ile birlikte hipoventilasyon, hipotalamik disfonksiyon ve otonomik disregülasyon sendromu ile karakterize nadir görülen bir hastalıktır (Kocaay, 2014). Gayet sağlıklı geçen 1,5-2 seneden sonra, 2-4 yaş arasında hiperfaji, dramatik kilo alımı ve gelişimin yavaşlaması ile hastalığın ilk semptomları görülmeye başlar. Hızlı başlangıçlı obeziteyi hipotalamik disfonksiyonun karakteristik semptomları (sıvı balansında bozulma, büyüme hormonu eksikliği, hipotiroidizm, adrenal yetmezlik ve bozulmuş puberte başlangıcı), alveolar hipoventilasyon ve otonomik disregülasyon (oftalmolojik belirtiler, gastrointestinal dismotilite, termal disregülasyon, bozulmuş vazomotor tonüs, artmış ağrı eşiği ve nöral tümörler) izlemektedir. Vakaların \%40’ından fazlası nöral tümörlerle ilişkilidir. (Kocaay, 2014; Ibánez-Micó, 2017; Barclay, 2018; Valea, 2014). Genetik altyapısı kanitlanamamakla birlikte, PHOX2B genindeki mutasyonun santral hipoventilasyona neden olduğu belirtilmektedir. Hastalıkla ilgili bilgiler çok azdır, bildirilen mortalite oranı ise \%50-60’tan daha yüksektir (Jalal Eldin, 2019).

Tedavide ise ventilasyonun yönetilmesi başlıca konulardandır. Bozulmuş ventilasyon, nörokognitif ve davranışsal bozulmalara neden olabilmektedir. Bu nedenle evde etkili bir non-invaziv ventilasyon uygulaması ve uyku saatlerinin düzenli olması, hastanın yaşına göre normal hareketler sergilemesi için önemlidir. Medikal tedavide ise yüksek doz siklofosfamidin, vücut kütle indeksi ve nöropsikolojik fonksiyonlara pozitif etkisinin olduğu bildirilmiştir (Harvengt, 2020).

Diğer hastalık gruplarından farklı olarak oldukça nadir görülen ROHHAD sendromunda tanı, tedavi ve prognozun karmaşık süreci hasta ve ailesini çok yönlü alanlarda etkilemektedir. Bu durumda hasta ve ailesinin uzun bir süreci kapsayacak bakım gereksinimleri ortaya çıkmaktadır. Hemşirelik bakımı, merkezine insanı alan bütüncül bir bakış açısına sahip olmalıdır. Kanıta dayalı ve etkin girişimler için kuramlara dayalı bakım verilmesi ile daha olumlu sağlık çıktıları elde edilecektir. King'in Amaca Ulaşma Kuramı çerçevesinde hemşireler; hastanın kendisi, ailesi ve çevresi ile etkileşim içinde olduğu zaman hasta ve ailesinin yaşamında pozitif etkiler oluşmaktadır. Ayrıca taburculuk sonrası dönemde de hasta ve ailesi süreç yönetiminde daha etkili olabilmektedir (Deniz, 2017; Uğur, 2017; Araujo, 2018).

\section{İmogene King’in Amaca Ulaşma Kuramı}

King, 1971'de kavramsal çerçevesini oluşturduğu çalışmasını zamanla geliştirip Amaca Ulaşma Kuramı olarak 1981'de yayınlamıştır. Teoride insanların hemşirenin odak noktası olduğu varsayılmaktadır. Hemşirelerin amacı; sağlığın desteklenmesi, sürdürülmesi, rehabilitasyon ve 
hastalık, travma, yaşam sonu dönemde bakımdır. Hemşirelik alanı; hemşirelerin çoklu etkileşim içinde olduğu insanları, aileleri ve toplumları içermektedir. (King, 1992).

Kavramlar sisteminde amaç, üç dinamik etkileşimli sisteme kapsamlı bir bakış açısı sağlamaktır. Bu üç sistem; kişilerin, grupların ya da toplumların büyümesini, gelişmesini, sağlığını ve çalışmasını etkileyen çevreleri temsil etmektedir (Şekil-1). Bu genel sistemlerin yapısında belirgin amaçlar vardır ve bu da kişinin, grupların ve toplumların sağlığıdır (King, 1997). Bunlar;

Kişisel Sistemler; Bireylerin kendisi oluşturmaktadır. Her birey, çevresi ile etkileşim ve iletişim içinde bulunan bir sistemdir.

Kişilerarası Sistemler; İki veya daha fazla kişinin etkileşimi sonucu oluşur. Özellikle hemşire ve hasta arasındaki etkileşim sonucu oluşmaktadır. Bu iletişim karşıdaki kişiyi anlamaya yöneliktir. Genellikle tanılamak amacıyla yargılayıcıdır ve amaçları etkileyebilir.

Sosyal Sistemler; ortak hedefi olan bireylerin oluşturduğu büyük gruplardan meydana gelmektedir (aile, şirket, toplum gibi). Sosyal sistemler ile olan iletişim bireyi çok yönlü etkilemektedir (Frey, 2002; Hajbaghery, 2018).

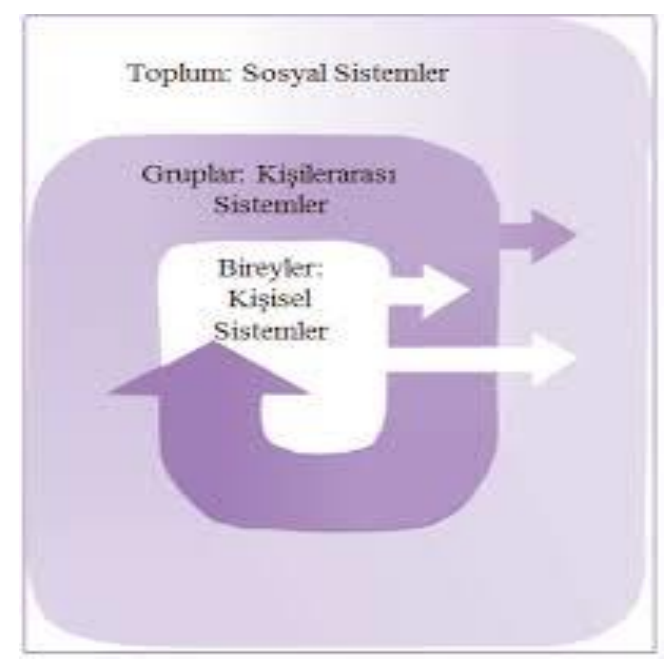

Şekil 1. King'in Kavramlar Sistemi

Amaca Ulaşma Kuramı ise King'in Kavramsal Sistemler modelinden elde edilmiştir. Majör 11 kavram bulunmaktadır; algılama, iletişim, karş11ılı etkileşim, etkileşim, öz, rol, büyüme ve gelişme, stres/stresör, baş etme, zaman ve kişisel alandır (King, 1997). Hemşire ile hasta ve/veya ailesi arasında etkileşim başladığında amaca ulaşılacağı öngörülmektedir (Şekil-2). Yine hemşirenin uyguladığı girişimler etkileşimi başlatacağı için amaca ulaşılacaktır. Teoride, amaca ulaşmada yol gösterici olan hemşire-hasta iletişiminin doğası betimlenmiştir. Amacın belirlenmesinde hemşirenin; hastanın endişelerini, problemlerini, sağlıktan sapmalarını tanılaması ve bilgileri hasta ve ailesi ile paylaşması önemlidir (King, 1992). Eğer hemşire-hasta etkileşimi gerçekleşirse amaçlara ulaşlacaktır. Hemşire ve hastanın, rol beklentisi ve rol performansı uyumlu olursa, etkileşim oluşacaktır. Bilgili ve becerikli bir 
hemşire, uygun bilgileri hasta ile paylaşırsa, ortak amaçlar düzenleme ve amaçlara ulaşma görülecektir (Alligood, 2010).

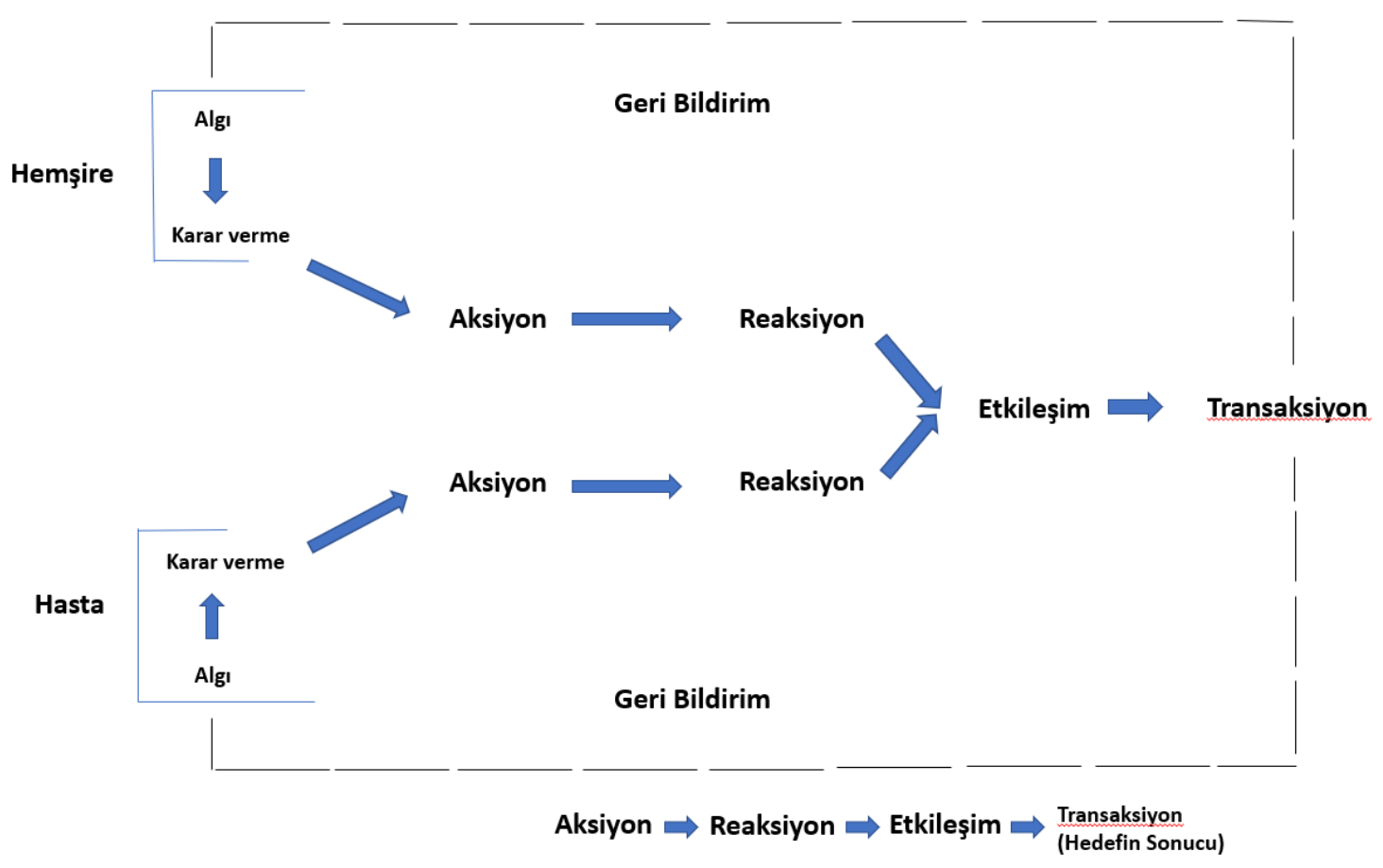

Şekil 2. King'in Amaca Ulaşma Teorisi

Ayrıca kuramda; Amaca Ulaşma Kuramı ve klasik hemşirelik süreci arasındaki bağlantı da açıklanmakta ve Amaca Ulaşma Kuramı'nda bahsedilen hemşirelik süreci geleneksel hemşirelik sürecinden ayrı tutulmaktadır (King, 1997).

Tablo 1. Kuram ve Yöntem Olarak Hemşirelik Süreci

\begin{tabular}{|l|l|}
\hline Bir Yöntem Olarak Hemşirelik Süreci & Bir Kuram Olarak Hemşirelik Süreci \\
\hline Birbiriyle İlişkili Eylemler Sistemi & Birbiriyle İlişkili Kavramlar Sistemi \\
Veri Toplama & Hemşire ve Hastanın Algısı \\
Planlama & Hemşire ve Hastanın İletişimi \\
Uygulama & Hemşire ve Hastanın Etkileşimi \\
Değerlendirme & Hedefler Hakkında Karar Verme \\
& Hedeflere Ulaşmak İçin Aynı Fikirde Olma Etkileşimde \\
& Bulunma (Faaliyete Geçme) \\
& Amaca Ulaşma (Eğer ulaşıllamadıysa nedeni?) \\
\hline
\end{tabular}

\section{OLGU SUNUMU}

BG 17 yaşında kız hasta. Beş yaşında başlayan çevreye zarar verme eğilimi, obezite ve fazla yemek yeme yakınması ile endokrin servisine başvuran hastaya ROHHAD sendromu tanısı 
konmuştur. Takip eden süreçte hipotirodi, hipokortizolemi, hipernatremiye eşlik eden hipotermi, pnömoni, solunum yetmezliği (hipoventilasyon/ hipoksemi/ hiperkarbi) tanılarıyla tekrarlayan yoğun bakım yatış/çıkış öyküsü bulunan hastaya, uzamış mekanik ventilasyon süreci sonrasında 2016 yılında dış merkezde trakeostomi açılarak taburcu edilmiştir.

Son iki aydır bakım evinde bilinç açık koopere izlenirken solunum arrestini takiben kardiyak arrest gelişen hastaya 112 ekibi tarafından 10 dakika süreyle CPR (Cardiopulmonary Resuscitation, Kardiyopulmoner Resüsitasyon) uygulanmıştır. Geliş nörolojik muayenesinde Glaskow Koma Skalası Puanı (GKS) 5 olan ve hipotansiyon gelişen (MAP: $65 \mathrm{mmHg}>$ ) hastaya yeterli sıvı replasmanı sonrasında laktat takibi yapılarak nöradrenalin infüzyonu başlanmış ve eş zamanlı olarak tüm kültür örnekleri alınarak uygun antibiyoterapi (piperasilin tazobaktam) uygulanmıştır. Onuncu günde noradrenalin infüzyonu kapatılan ve mekanik ventilatörden ayrılan hasta 13.günde bilinç açık koopere spontan solunumda dış merkeze sevk edilmiştir. 
SABAD, 2020; 2(2), 131-140

\section{Imogene King'in Kavramsal Sistem Modeli’ne Göre Hemşirelik Bakım Planı}

\begin{tabular}{|c|c|c|c|}
\hline $\begin{array}{l}\text { Algı, iletişim ve hasta hemşire } \\
\text { etkileşimi }\end{array}$ & $\begin{array}{l}\text { Amaçlarının Belirlenmesi } \\
\text { Ve Amaçların Başarılması }\end{array}$ & Amaçlı Etkileşim Yapma & Amacın Başarılması \\
\hline $\begin{array}{l}\text { Hemşirenin Hastayı Algılaması: } \\
\text { BG, solunum arrestini takiben } \\
\text { kardiyak arrest ile yoğun } \\
\text { bakımımıza kabul edilmiştir. } \\
\text { Hastada trakeostomi mevcut, } \\
\text {,mekanik ventilatör aracıllğı ile } \\
\text { solunumu sağlanıyor. } \\
\text { ETKİSiz } \\
\text { ÖRÜNTÜSÜ }\end{array}$ & $\begin{array}{lr}\text { Hastanın } & \text { mekanik } \\
\text { ventilatörden } & \text { ayrılarak } \\
\text { spontan } & \text { solumasının } \\
\text { sağlanması. } & \end{array}$ & $\begin{array}{l}\text {-Hasta monitörize edilerek vital bulguları takip edildi. } \\
\text {-Hastanın solunum sayısı, derinliği ve niteliği takip edildi. } \\
\text {-Oksijen satürasyonu yakından takip edildi. } \\
\text {-Gerek duyulduğunda aspire edildi. } \\
\text {-Bakım sırasında ajitasyonu tetiklemeyecek düzeyde postüral drenaj uygulandı. } \\
\text { - Aspire etmesini önlemek ve rahat oksijenlenmeyi sağlamak için yatak başı 45 } \\
\text { olacak şekilde kaldırıldı. } \\
\text {-Solunum yolu sekresyonlarının atılmasını kolaylaştırmak için hekim istemiyle } \\
\text { order edilen sıvı tedavisi, bronkodilatörler ve nebüller uygulandı. }\end{array}$ & $\begin{array}{l}\text { Onuncu günde mekanik } \\
\text { ventilatörden ayrılarak } \\
\text { alıştırma yaptırılmak için } \\
\text { termovent ile oksijen verildi. } \\
\text { 13. günde hasta spontan } \\
\text { solunum ile dış merkeze } \\
\text { sevkedildi. }\end{array}$ \\
\hline $\begin{array}{l}\text { Hemşirenin Hastayı Algılaması: } \\
\text { Annesi BG'nin evdeki bakımını } \\
\text { sürdürmekteydi. Yoğun bakım } \\
\text { sürecinde annesi yanında } \\
\text { bulunmayan BG'nin, ajite olduğu } \\
\text { için ekstremiteleri tespit edildi ve } \\
\text { bakımı hemşireler tarafından } \\
\text { üstlenildi. } \\
\text { ÖZ BAKIMDA YETERSIZLLIK }\end{array}$ & $\begin{array}{l}\text { Hastanın yoğun bakım } \\
\text { sürecinde öz bakımının } \\
\text { sağlanması. }\end{array}$ & $\begin{array}{l}\text {-Hastanın temizlik alışkanlığını değerlendirerek yetersizlik durumu tanımlandı. } \\
\text { (el-yüz temizliği, banyo. sıklığı, ağız bakımı, ayak bakımı, tırnak kesimi) } \\
\text {-SF ile yüz ve göz bakımı yapıldı. } \\
\text {-Ağız bakımı günde } 6 \times 1 \text { antiseptik solüsyon ile sağlandı. } \\
\text { - Ajite olduğu ve tırnakları ile kendini çizerek zarar vermemesi için tırnakları } \\
\text { kesildi. } \\
\text {-Yatak içi günlük vücut silmesi yapıldı. } \\
\text {-Hastanın inkontinansı olduğu için alt bakımı yapıldı. } \\
\text {-Hastanın bakımı verilirken mahremiyeti sağlandı. }\end{array}$ & $\begin{array}{l}\text { Hastanın yoğun bakımda } \\
\text { bulunduğu süre içerisinde öz } \\
\text { bakımı sağlandı. } \\
\text { Taburculuk sonrası evde } \\
\text { bakım için aileye eğitim } \\
\text { verildi. }\end{array}$ \\
\hline $\begin{array}{l}\text { Hastanın kendini algılaması: } \\
\text { Hastayla iletişim kurmaya } \\
\text { çalıştı̆̆ımızda cevap vermiyordu, } \\
\text { göz teması kurmuyordu ve ajiteydi. } \\
\text { Korkmuş yüz ifadesi göze } \\
\text { çarpıyordu. } \\
\text { Hemşirenin hastayı algılaması: } \\
\text { ILETişiMDE BOZULMA }\end{array}$ & $\begin{array}{l}\text { Gözlem süresi boyunca } \\
\text { hastayla en üst düzeyde } \\
\text { iletişimin sağlanması. }\end{array}$ & $\begin{array}{l}\text {-Hastayla göz teması kurularak, yüzüne bakılarak, açık ve net konuşuldu. } \\
\text { - Gürültü oluşturan ve dikkati dağıtan gereksiz sesler en aza indirildi. } \\
\text {-Hasta söyleneni anlamadığında aynı ses tonuyla, bağırmadan, kısa ve uygun } \\
\text { sözcüklerle cümleler tekrarlandı. Hastayla iletişim kurulurken çevreye yönelik } \\
\text { algılamasını sorgulamaktan çok çevreyi tanıtıcı ve doğru algılamayı } \\
\text { kolaylaştırıcı bilgilendirmelere yer verildi. } \\
\text {-Hasta cevap veremediğinde göz kırpma, parmak işaretleri gibi sözsüz iletişim } \\
\text { teknikleri kullanıldı. } \\
\text {-İletişimde olumsuz ifadelerden kaçınıldı. Cevap verebilmesi için zaman tanındı. } \\
\text {-Evet ve hayır gibi tek kelimeyle cevap verebileceği sorular soruldu. } \\
\text {-Hasta ile konuşma, hasta bir konuda sözlü veya sözsüz katılım sağlayıp sözlü } \\
\text { iletişimde başarılı olduğu bir zamanda sonlandırıldı. }\end{array}$ & $\begin{array}{l}\text { Hasta iletişim kurmak } \\
\text { istediğinde göz teması kurdu, } \\
\text { evet-hayır ile } \quad \text { cevap } \\
\text { verebileceği sorularda } \\
\text { iletişime daha kolay katıldı ve } \\
\text { iletişimi sürdürme daha } \\
\text { başarılı gerçekleşti. }\end{array}$ \\
\hline $\begin{array}{l}\text { Bakım verenin kendini } \\
\text { algılaması: } \\
\text { Annesi, çocukluktan itibaren } \\
\text { sürekli hastanede olduklarını ve } \\
\text { BG'nin kendine zarar verme } \\
\text { davranışlarını önleyemediklerini, } \\
\text { artık hayatın akışına yetişemediğini } \\
\text { söylemiştir. } \\
\text { Hemşirenin bakım vereni } \\
\text { algılaması: } \\
\text { BAKIM VERİCI ROLÜNDE } \\
\text { zORLANMA }\end{array}$ & $\begin{array}{l}\text { Takip süresi sonunda bakım } \\
\text { vericinin bakım rolünü } \\
\text { zorlanmadan } \\
\text { yapabilmesinin sağlanması } \\
\text { ve bakım verici de } \\
\text { tükenmişlik belirtilerinin } \\
\text { gözlenmemesi }\end{array}$ & $\begin{array}{l}\text {-Bakım rolünde zorlanmaya neden olan faktörler (bakıma yönelik algı, sosyal } \\
\text { izolasyon gibi) belirlendi. } \\
\text {-Bakım vericinin fiziksel ve emosyonel zorlanması üzerine konuşuldu. } \\
\text {-Bakım verici, annesinin bakımının iyi olması konusunda gösterdiği çaba için } \\
\text { takdir edildi. } \\
\text {-Bakım verici, destek alabilecekleri sivil toplum kuruluşları konusunda } \\
\text { bilgilendirildi ve bu konuda cesaretlendirildi. } \\
\text {-Bakım verici, stresle baş etme becerileri konusunda bilgilendirildi. } \\
\text { - Evde yaşayan diğer aile üyeleri ile bakım verme işinin olumlu ve olumsuz } \\
\text { etkileri, bakım vericiyi takdir etmenin, sorunları ile ilgilenmenin, dönemler } \\
\text { halinde dinlendirmenin, kendisine vakit ayırması için firsat vermenin ve yardım } \\
\text { etmeye hazır bulunmanın önemi konusunda tartışıldı. } \\
\text {-Bakım verici, yakınlarından yardım isteme konusunda cesaretlendirildi. } \\
\text {-Bakım vericiye kendi sağlığını koruması ve geliştirmesi konusunda } \\
\text { bilgilendirme yapıldı. }\end{array}$ & $\begin{array}{l}\text { Bakım vericiden bakım } \\
\text { vermenin oluşturduğu } \\
\text { zorluklarla mücadele etme } \\
\text { konusunda geri bildirim alındı. } \\
\text { Eşinin, eskiden BG ile çok } \\
\text { ilgilenmediğini, kendisine çok } \\
\text { destek olmadığını, fakat eşi ile } \\
\text { BG’nin bakımı konusunda } \\
\text { iletişim kurduktan sonra daha } \\
\text { iyi anlaştıklarını belirtti. }\end{array}$ \\
\hline
\end{tabular}




\begin{tabular}{|c|c|c|c|}
\hline $\begin{array}{l}\text { Bakım vericinin } \\
\text { algılaması: Annesi } \\
\text { normalde yürüyebildiğini fakat } \\
\text { sürekli düştüğünü, duvarlara } \\
\text { çaptığını, bu yüzden vücudunda } \\
\text { sürekli travma izlerinin olduğunu } \\
\text { belirtmiş̧tir. } \\
\text { Hemşirenin hastayı algılaması: } \\
\text { TRAVMA RíSKI }\end{array}$ & $\begin{array}{l}\text { Bakım verilen süre } \\
\text { içerisinde hastanın travma } \\
\text { ve düşme deneyimlemesini } \\
\text { önlemek. }\end{array}$ & $\begin{array}{l}\text { Hastanın güvenlik durumu ve travma riski tanımlandı (İtaki düşme riski ölçeği } \\
\text { puanı } 23 \text { 'dür.) } \\
\text { Bireyi ortama oryante edecek girişimler uygulandı. } \\
\text { Koruyucu önlemler konusunda hasta ve yakınları bilgilendirildi. } \\
\text { Hastanın pozisyonu yavaş yavaş değiştirildi.. } \\
\text { Yatak seviyesi azaltıldı. } \\
\text { Hastanın ajitasyonu olduğu için tespit uygulandı ve saat başı tespit kontrol edildi. } \\
\text { Hastanın oryantasyonu arttıkça ve ajitasyonu azaldıkça tespitler gevşetildi ve } \\
\text { kaldırıldı. } \\
\text { Mümkün olduğunca kolay müdahale edilebilecek, hemşire deskine yakın bir } \\
\text { yatakta takip edildi. } \\
\text { Sık sık hasta gözlemlendi. } \\
\text { Yatağın alçak seviyede ve kolluklarının kaldırılmış şekilde olması sağlandı. }\end{array}$ & $\begin{array}{l}\text { Düşme ya da travma } \\
\text { bildirilmedi. } \\
\text { İtaki puanı:13 } \\
\text { Geçmiş travma bulguları } \\
\text { dişında vücudunda travma ve } \\
\text { düşme bulgusuna rastlanmadı. }\end{array}$ \\
\hline $\begin{array}{l}\text { Hemşirenin hastayı algılaması: } \\
\text { BG'nin daha önce aspirasyon } \\
\text { öyküsünün bulunması, nazogastrik } \\
\text { sonda ile enteral beslenmesi, } \\
\text { trakeostomisinin bulunması, ajite } \\
\text { olması. } \\
\text { ASPIRASYON RİSKİ }\end{array}$ & $\begin{array}{l}\text { Bakım verilen süre } \\
\text { içerisinde hastanın aspire } \\
\text { etmesini önlemek }\end{array}$ & $\begin{array}{l}\text {-Hastanın yutma durumu ve yutma refleksi gözlenerek değerlendirildi. } \\
\text {-Hastanın vital bulguları (özellikle solunum) takip edildi. } \\
\text {-Beslenme sırasında ve beslendikten sonra hasta dik oturtuldu. } \\
\text {-Beslemeye başlamadan önce tüpün yerinde olup olmadığı kontrol edildi. } \\
\text {-Gastrik rezidü kontrol edildi. } \\
\text {-Besleme öncesi hastanın başı } 30-45^{\circ} \text { yükseltildi. } \\
\text {-Günde 6x1 antiseptik gargara ile ağız bakımı uygulandı. } \\
\text {-Sekresyon durumu değerlendirilerek sık aspire edildi. } \\
\text {-Taburculuk için hastaya bakım verecek kişi olan annesine eğitim verildi. }\end{array}$ & $\begin{array}{l}\text { Aspirasyon bulguları } \\
\text { gözlenmedi } \\
\text { (hiperventilasyon,desaturasyon } \\
\text { gelişmedi,sekresyon } \\
\text { miktarında koyulaşma ve } \\
\text { artma olmadi.) }\end{array}$ \\
\hline $\begin{array}{l}\text { Hemşirenin hastayı algılaması: } \\
\text { BG'nin santral kateterinin, } \\
\text { trakeostomisinin, üriner ve } \\
\text { nazogastrik sondasının } \\
\text { bulunması,13 boyunca yoğun } \\
\text { bakımda yatmış olması. }\end{array}$ & $\begin{array}{l}\text { Yoğun bakımda yattığı süre } \\
\text { içerisinde } \\
\text { enfeksiyon hastada } \\
\text { önlemek }\end{array}$ & $\begin{array}{l}\text {-BG'de olası risk faktörleri tanımlandı ve değerlendirildi. } \\
\text {-Enfeksiyonun klinik belirtileri (ateş, ağrı, idrarda bulanıklık, pürülan } \\
\text { akıntı vb.) takip edildi. } \\
\text {-El hijyenine özen gösterildi ve diğer çalısanlar bu konuda uyarıldı. } \\
\text {-Enfeksiyon gelişmesini önlemek için standart önlemler alındı. } \\
\text {-Gereksiz invaziv uygulamalardan kaçınıldı } \\
\text {-İnvaziv girişimlerde aseptik tekniğe dikkat edildi ve konuda diğer sağlık } \\
\text { çalışanları uyarıldı. } \\
\text {-Vital bulguları takip ve kayıt edildi. } \\
\text {-Bg'de bulunan invaziv araçların bakımı (nazogastrik sonda, foley kateter, } \\
\text { santral kateter, arter kateterizasyonu) rehberlere uygun olarak yapıldı. } \\
\text {-İnvaziv girişim yerleri enfeksiyon belirtileri yönünden takip edildi (akıntı, } \\
\text { kızarıklık, 1sı artışı gibi). } \\
\text {-Taburculuk için hastaya bakım verecek kişi olan annesine eğitim verildi. }\end{array}$ & $\begin{array}{l}\begin{array}{l}\text { Takip süresi } \\
\text { enfeksiyon }\end{array} \\
\text { gözlenmedi } \\
\begin{array}{l}\text { (Vücut sılguları } \\
\text { arasında }\end{array} \\
\begin{array}{ll}\text { CRP,BNP,Lökosit } & \text { ve Laktat } \\
\text { değerlerinde } & \text { yükselme } \\
\text { olmadı). }\end{array}\end{array}$ \\
\hline
\end{tabular}

\section{TARTIŞMA ve SONUÇ}

King'in Kavramsal Sistem Kuramı hemşirelik sürecinin planlama ve uygulama aşamalarını içerdiğinden özellikle hemşire ve hasta arasındaki etkileşim odaklı girişimlere yoğunlaşılmasına olanak sağlar. Aksuoğlu ve arkadaşlarının yapmış olduğu çalışmada; King'in Amaca Ulaşma Kuramı'nın hemşirelik bakımında uygulanması ile hastanın kendi bakımında otonomi sahibi olmasının sağlandığı belirtilmiştir (Aksuoğlu, 2018). Başka bir çalışmada ise Alzheimer hastalarına King'in kuramı doğrultusunda verilen bakımın, hasta/bakım verici-hemşire etkileşimini desteklediği ifade edilmiştir (Uğur, 2017). Bu çalışmada, ROHHAD sendromu bulunan hastanın yoğun bakım sürecinde King'in Kavramsal Sistem Modeli'ne göre hemşirelik bakımı verilmiştir. King'in Kavramsal Sistem Modeli'ne göre ROHHAD sendromu hastasına uygulanan hemşirelik bakımının, hasta/ bakım verici- 
hemşire etkileşimini desteklediği belirlenmiştir. Bireyin tüm yönleriyle değerlendirilmesini sağlamakta, hemşirelik uygulamalarında son derece gelişmiş düşünme becerilerini gerektirmekte, böylece bakımın kalitesini arttırmaktadır. Deniz ve arkadaşlarının yapmış olduğu çalışmada; King'in Amaca Ulaşma Kuramı çerçevesinde verilen bakımın, hastanın sağlık çıktılarına pozitif etkisi olduğu bildirilmiştir (Deniz, 2017). Bu kuramın hemşirelik süreci ile uyum göstermesi, kuramın uygulanabilirliği ve sürdürülebilirliği açısından önemlidir. 


\section{KAYNAKLAR}

Alligood, M.R. (2010). Family healthcare with King's Theory of goal attainment. Nursing Science Quarterly, 23(2), 99-104. doi: 10.1177/0894318410362553

Araújo, E.S.S., Silva, L.F., Moreira, T.M.M., Almeida, P.C., Freitas, M.C., \& Guedes, M.V.C. (2018). Nursing care to patients with diabetes based on King's Theory. Revista Brasileria de Enfermagem [Internet], 71(3),1092-8. doi: 10.1590/0034-7167-2016-0268.

Aksuoğlu, A., Yanmış, S. ve Deşer, S.B. (2018).Yoğun bakım ünitesinde Imogene King' in Kavramsal Sistem Modeline göre bir kalp cerrahisi hastasının hemşirelik bakımı: olgu sunumu. SETSCI Conference Indexing System, 3, 973-975.

Barclay, S.F., Rand, C.M., Nguyen, L., Wilson, R.J.A., Wevrick, R., Gibson, W.T. et al. (2018). ROHHAD and Prader-Willi syndrome (PWS): clinical and genetic comparison. Orphanet Journal of Rare Diseases, 13, 124. doi: 10.1186/s13023-018-0860-0.

Deniz, A., Yıldırım, Y., Fadıloğlu, Ç., \& Aykar, F.Ş. (2017). A case of heart failure in the framework of King's Theory of goal attainment. Journal of Cardiovascular Nursing, 8(16), 63-7. doi: 10.5543/khd.2017.83007

Frey, M.A., Sieloff, C.L. \& Norris, D.M. (2002). King's conceptual system and theory of goal attainment: past, present and future. Nursing Science Quarterly, 5(2), 107-112. doi: $10.1177 / 089431840201500204$

Hajbaghery, M.A. \& Tahmouresi, M. (2018). Nurse-patient relationship based on the Imogene King's theory of goal attainment. Nursing and Midwifery Studies, 7, 141-4. doi: 10.4103/23221488.235636

Harvengt, J.,Gernay, C., Mastouri, M., Farhat, N., Lebrethon, M.C., Seghaye, M.C. et al. (2020). ROHHAD(NET) syndrome: systematic review of the clinical timeline and recommendations for diagnosis and prognosis. Journal of Clinical Endocrinol Metabolism,105(7),1-13. doi: 10.1210/clinem/dgaa247

Ibánez-Micó, S., Marcos A.M., de Murcia Lemauviel, S., Ruiz Pruneda, R., Martínez Ferrández, C., Domingo Jiménez, R. (2017). Rapid-onset obesity with hypothalamic dysregulation, hypoventilation, and autonomic dysregulation (ROHHAD syndrome): A case report and literature review. Neurología, 32, 616-622. doi: 10.1016/j.nrl.2016.04.008.

Jalal Eldin, A.W., Tombayoğlu, D., Butz, L., Affinati, A., Meral, R., Ontan, M.S. et al. (2019). Natural history of ROHHAD syndrome: development of severe insulin resistance and fatty liver disease over time. Clinical Diabetes and Endocrinology, 5(9). doi: 10.1186/s40842-019$0082-\mathrm{y}$ 
King, I.M. (1992). King's theory of goal attainment. Nursing Science Quarterly, 5(1),19-26. doi: $10.1177 / 089431849200500107$

King, I.M. (1997). King's theory of goal attainment in practice. Nursing Science Quarterly, 10, 180. doi: $10.1177 / 089431849701000411$

Kocaay, P., Şıklar, Z., Çamtosun, E., Kendirli, T. \& Berberoğlu, M. (2014). ROHHAD Syndrome: reasons for diagnostic difficulties in obesity address for correspondence. Journal of Clinical Research In Pediatric Endocrinology, 6(4), 254-257. doi: 10.4274/jcrpe.1432

Uğur, H.G., Orak, O.S., Alkan, S.A. \& Yüksel, Ş. (2017). Examination of a patient with Alzheimer's Disease at home according to the conceptual system model of Imogene King: A case study. Journal of Psychiatric Nursing, 8(1), 48-53. doi: 10.14744/phd.2017.41736

Valea, A., Silaghi, C.A., Ghervan, C.M.V., Silaghi, H., Florea, M., Simionescu, B. et al. (2014). Morbid child obesity with possible ROHHADNET- ROHHAD syndrome. case report. Acta Endocrinologica, (3), 515-524. doi: 10.4183/aeb.2014.515 